\title{
Sleep Habits and Disorders among school students in the Jazan Region, Saudi Arabia
}

\author{
Majed I. Hakami ${ }^{1}$, , Ismail A. Juraybi ${ }^{1}$, Abdullah A. Jaafari ${ }^{1,3}$, Ali M. Al-Ibrahim ${ }^{1}$, Alhasaan M. \\ Kariri $^{1}$, Ali M. Kariri ${ }^{1}$, Basim Y. Khawaji ${ }^{1}$, Almonther H. Wassly ${ }^{1}$, Siraj O. Wali ${ }^{2}$, Faris F. \\ Alhejaili $^{2}$ and Jeraiby Mohammed ${ }^{4}$
}

1 King Fahad Central Hospital, Jazan, Saudi Arabia

2 King Abdulaziz University Hospital, Jeddah, Saudi Arabia

3 King Faisal Specialist Hospital and Research Center-Jeddah, Saudi Arabia

4 Medical Biochemistry Department, Faculty of Medicine, Jazan University, Saudi Arabia

* Correspondence: author: Majed I. Hakami, Consultant,pulmonology and sleep medicine, King Fahad Central Hospital, Gizan, Saudi Arabia; hakamy99@hotmail.com; +966567172275

\begin{abstract}
Sleep deprivation (failure to get enough sleep) is a public health issue that can negatively impact our body including cognitive function. Many studies have been done in Saudi Arabia to evaluate the impact of poor sleep and academic performance but almost all of them were done at university level. To investigate the relationship between sleep quality and general degree of academic achievement in school students. This is a cross-sectional, school-based study, conducted at Jazan Region, Saudi Arabia. A total of 957 participants (615 male and 342 female) were recruited from a state school. The study used a standardized, confidential, validated self-administered questionnaire to assess sleep quality and habits. By using Statistical Package for Social Studies (SPSS 22), achievement of the students was significantly related to the following parameters; laziness and fatigue after wake-up time and during school time, lack of concentration during school time, difficulty in complete tasks during school time and inability to maintain wakefulness during school time. Furthermore, students with poor academic degrees reported more significant incidence of sleeping at school, excessive daytime sleepiness, and other sleep related disorder than good academic degrees. Students with poor sleep quality have lower school grades.
\end{abstract}

Keywords: Sleep habits; Sleep disorders; Students: Academic achievement.

\section{Introduction}

Sleep is a vital component of one's health, well-being, and functioning. The recommended hours of sleep per day for school age children is 9-12 hours for 6-12-year-olds and 8-10 hours for teens 13-18 years old, according to the American Academy of Sleep Medicine and the Sleep Research Society ${ }^{[1]}$. Adults age 18-60 years need to sleep at least 7 hours per day ${ }^{[2]}$. Today, adolescents sleep less, and experience more daytime symptoms of sleepiness compared to previous generations ${ }^{[3]}$. A study was done at Taibah University, Saudi Arabia to evaluate the impact of sleep habits on academic achievement among fourth year medical students. That study determined that poor sleep quality was significantly correlated with decreased academic performance ${ }^{[4]}$. Another study on the changes in sleep habits among children and adolescents in Sweden conducted from 1985 to 2013 
demonstrates that over time fewer children and adolescents attained enough sleep duration. This had a significant implication for the study results, mental health, and cognitive impairment ${ }^{5]}$. During adolescence, sleep habits undergo major changes, including a decrease in sleep duration and depth. In addition, adolescents experience a tendency to sleep during evening hours due to internal and external influences on the brain mechanisms regulating sleep and circadian rhythm [6]. Much research has drawn a strong relationship between mental health and sleep. Non-sufficient sleep also called sleep deprivation, in children and adolescents is correlated with both short term and long term negative outcomes for mental and somatic health $[7,8]$. Enough sleep time and lack of trouble falling asleep predict self-related good psychological health and the absence of psychosomatic health complaints in children and adolescents [9]. Moreover, the use of electronic media late in the day, such as mobile phones, video games consoles, televisions, computers, and tablets are associated with increased mood disturbances [10]. Repeating episodes of inadequate sleep are characterized as chronic partial sleep deprivation. Altogether, the results signal that alternations in sleep habits may impact the mental health of a population. With the above, in mind this study proposed to evaluate the prevalence of positive and negative sleep habits and try to define the relationship between sleep quality and academic performance among students.

\section{Methods and Materials}

This was a cross-sectional study conducted in the Jazan region, which has a population of more than one million and three hundred thousand [11]. A group of sixth year medical students processed it. The Jazan Institutional Review Board (IRB) did ethical approval, with approval no. 1919. The target population was elementary (6-11 years), intermediate (12-15 years), and secondary (16-18 years) school students. Ethical considerations were followed in agreement with the Declaration of Helsinki throughout this study and it was approved by the Research Committee / Jazan IRB (H-10-Z-068), Kingdom of Saudi Arabia (Reference No. 1919).

\section{Study design and data collection}

Data was collected daily, except weekends (Friday and Saturday), for three months on government school students above six years of age, including male and female, Saudi and non-Saudi. Multistage cluster random sampling was the method used to collect data. The schools were divided into coastal, island, mountain, and plains areas. Schools were randomly selected depending on the classifications mentioned above. Then, students were chosen randomly in each school. All participants were advised that they have the right to not participate and that their information would be kept anonymous and confidential.

\section{Sleep quality questionnaire}

The study used a standardized, confidential, validated selfadministered questionnaire to assess sleep quality and habits and Epworth sleepiness scale for daytime sleepiness. The questionnaire covered the following topics: demographic data sleep nature and environment, sleep habits, daily activity, sleep disorders, and evaluation of sleep quality. All students filled out the questionnaire by themselves 
except for the elementary school students, whose parents completed the questionnaire with information regarding their child.

\section{Statistical analysis:}

Data were analyzed by using Statistical Package for Social Studies (SPSS 22; IBM Corp., New York, NY, USA). Continuous variables were expressed as mean \pm standard deviation and categorical variables were expressed as percentages. One way ANOVA was used for continuous variables. The Cronbach's alpha was used to assess the reliability the questionnaire. Pearson correlation coefficient was used to assess the Correlation between sleep quality and general degree of academic achievement in school students. A p-value $<0.05$ was considered statistically significant.

\section{Reliability of the questionnaire}

The Cronbach's alpha for Daily activities, Sleep disorder, Epworth Sleepiness were $0.821,0.817$, and 0.584 respectively which reflect acceptable and good reliability.

\section{Results}

A total of 957 students between the ages of 6-18 years old were included. Of these, $64.30 \%$ were males and $35.70 \%$ were females. $95.70 \%$ of total participants were Saudi nationals. $87.40 \%$ were rural, and $83.80 \%$ were living in the coastal area, the highest degree was excellent $(60 \%)$ while the failure was only $0.5 \%$. Most of students living standard building, traditional house was 53\% and 30\% respectively. All included students are studying in state school (Table 1).

\begin{tabular}{|c|c|c|c|}
\hline \multicolumn{4}{|c|}{ Table1 : Socio-demographic characteristics for the participants } \\
\hline Characteristics & Variables & Number $(\mathrm{N}=950)$ & $\%$ \\
\hline \multirow{2}{*}{ Gender } & male & 611 & 64.3 \\
\hline & female & 339 & 35.7 \\
\hline \multirow{2}{*}{ Nationality } & Saudi & 895 & 95.7 \\
\hline & Non Saudi & 40 & 4.3 \\
\hline \multirow{2}{*}{ Geographical Area } & coast & 762 & 83.8 \\
\hline & mountain & 147 & 16.2 \\
\hline \multirow{2}{*}{ Residency } & Urban & 116 & 12.6 \\
\hline & Rural & 806 & 87.4 \\
\hline \multirow{5}{*}{ General degree } & excellent & 555 & 60.3 \\
\hline & very good & 263 & 28.6 \\
\hline & good & 90 & 9.8 \\
\hline & pass & 7 & .8 \\
\hline & fail & 5 & .5 \\
\hline \multirow{4}{*}{ Type of house } & apartment & 79 & 8.5 \\
\hline & villa & 83 & 9.0 \\
\hline & building & 490 & 52.9 \\
\hline & traditional house & 274 & 29.6 \\
\hline Type of school & state school & 948 & 100.0 \\
\hline \multirow{3}{*}{ Educational level } & elementary & 212 & 22.7 \\
\hline & intermediate & 342 & 36.6 \\
\hline & secondary & 380 & 40.7 \\
\hline \multirow{6}{*}{ Educational stage } & 1 & 155 & 18.7 \\
\hline & 2 & 232 & 28.0 \\
\hline & 3 & 295 & 35.6 \\
\hline & 4 & 42 & 5.1 \\
\hline & 5 & 52 & 6.3 \\
\hline & 6 & 53 & 6.4 \\
\hline
\end{tabular}

Sleeping with others in the same room was reported for $73.40 \%$ of participants. However, only $10.80 \%$ were sleeping with anyone else in 
the same bed. Most students found light and noise in the bedroom disruptive and it affect their sleep $(73.30 \%$ and $82.10 \%$, respectively) (Table 2).

\begin{tabular}{|c|c|c|c|}
\hline \multicolumn{4}{|c|}{ Table 2. Sleep nature and environment } \\
\hline Environmental factors & Answer & Number $(\mathrm{N}=950)$ & $\%$ \\
\hline \multirow{2}{*}{ Effect of light } & yes & 696 & 73.3 \\
\hline & no & 254 & 26.7 \\
\hline \multirow{2}{*}{ Effect of noise } & yes & 780 & 82.1 \\
\hline & no & 170 & 17.9 \\
\hline \multirow{2}{*}{ Room temperature } & yes & 474 & 50.2 \\
\hline & no & 470 & 49.8 \\
\hline \multirow{2}{*}{ Effect of humidity } & yes & 334 & 35.6 \\
\hline & no & 603 & 64.4 \\
\hline \multirow{2}{*}{ Bed quality } & yes & 192 & 20.2 \\
\hline & no & 757 & 79.8 \\
\hline \multirow{2}{*}{ Sleep with other at same room } & yes & 692 & 73.4 \\
\hline & no & 251 & 26.6 \\
\hline \multirow{2}{*}{ Sharing of bed with any member } & yes & 102 & 10.8 \\
\hline & no & 843 & 89.2 \\
\hline
\end{tabular}

More than half of students fell asleep at 9-12 p.m. and over twothirds $(65.30 \%)$ waked up at $4-6$ a.m. The largest proportion $(35.90 \%)$ of participants in the current study slept for 4-6 hours, followed by $34.40 \%$ sleeping 6-8 hours. Only 52.50\% were satisfied with their amount of sleep and $25.10 \%$ reported it was not enough, as shown in Table 3.

\begin{tabular}{|c|c|c|c|}
\hline \multicolumn{4}{|c|}{ Table 3 : Sleeping habits } \\
\hline Sleep habits during school time & Variables & Number $(\mathrm{N}=950)$ & $\%$ \\
\hline \multirow{4}{*}{ Daily sleep time } & $6-9 \mathrm{pm}$ & 125 & 13.3 \\
\hline & 9-12 pm & 488 & 51.7 \\
\hline & $12-3 \mathrm{am}$ & 284 & 30.1 \\
\hline & after 3 am & 46 & 4.9 \\
\hline \multirow{4}{*}{ Wake up time during morning } & 3-5 am & 594 & 65.3 \\
\hline & 5-7 am & 217 & 23.8 \\
\hline & 7-9 am & 50 & 5.5 \\
\hline & after 9 am & 49 & 5.4 \\
\hline \multirow{4}{*}{ Average daily sleep } & $4-6 \mathrm{hrs}$ & 327 & 35.9 \\
\hline & $6-8 \mathrm{hrs}$ & 313 & 34.4 \\
\hline & 8-10 hrs & 167 & 18.3 \\
\hline & more than $10 \mathrm{hrs}$ & 104 & 11.4 \\
\hline \multirow{4}{*}{ Satisfaction of sleep } & not enough & 232 & 25.1 \\
\hline & less than enough & 156 & 16.8 \\
\hline & enough & 486 & 52.5 \\
\hline & more than enough & 52 & 5.6 \\
\hline \multirow{4}{*}{ Mean reason interrupts your sleep } & light & 196 & 21.3 \\
\hline & noise & 448 & 48.6 \\
\hline & sharing bed & 45 & 4.9 \\
\hline & $\begin{array}{c}\text { not affecting from } \\
\text { above }\end{array}$ & 233 & 25.3 \\
\hline \multirow{4}{*}{ Use drug to sleep } & always & 20 & 2.1 \\
\hline & sometimes & 51 & 5.4 \\
\hline & rarely & 55 & 5.8 \\
\hline & never & 824 & 86.7 \\
\hline \multirow{4}{*}{ Use drug to wakeful } & always & 22 & 2.3 \\
\hline & sometimes & 39 & 4.1 \\
\hline & rarely & 51 & 5.4 \\
\hline & never & 832 & 88.1 \\
\hline \multirow{4}{*}{ Use power drink to wakeful at night } & always & 65 & 6.9 \\
\hline & sometimes & 213 & 22.5 \\
\hline & rarely & 185 & 19.5 \\
\hline & never & 485 & 51.2 \\
\hline \multirow{2}{*}{ Mean reason for sleep } & feeling sleepy & 287 & 30.4 \\
\hline & parents & 153 & 16.2 \\
\hline
\end{tabular}




\begin{tabular}{|c|c|c|c|}
\hline & $\begin{array}{c}\text { wake up early for } \\
\text { work }\end{array}$ & 392 & 41.5 \\
\hline & usual time to sleep & 113 & 12.0 \\
\hline \multirow{4}{*}{ Mean reason for wake up } & by myself & 205 & 21.9 \\
\hline & noise & 49 & 5.2 \\
\hline & parents & 514 & 55.0 \\
\hline & alarm & 166 & 17.8 \\
\hline \multirow{4}{*}{ Attitude at bed for sleep } & use the mobile phone & 438 & 46.8 \\
\hline & thinking & 296 & 31.6 \\
\hline & $\begin{array}{l}\text { listening as (Quran, } \\
\text { story, music) }\end{array}$ & 123 & 13.1 \\
\hline & reading & 79 & 8.4 \\
\hline
\end{tabular}

The largest proportion of students reported that noisy environment was the main reason of sleep interruption. The large proportion of student fell asleep without medication, small number of students $(2.10 \%)$ use medication regularly to sleep. Use of drug as a stimulant to promote wakefulness was also rare between students and only $2.30 \%$ always using drug to maintain wakefulness. In other hand, only $51.20 \%$ of students didn't use power drink to keep them awake, and about half of them use it to maintain wakefulness. The main reason facilitating sleep was wake up early for work and parents played a role in initiation of sleep in $16.20 \%$ of students. In other hand, parents waked up the students included in the study in the majority followed by self wake-up in the morning for the school in 55\% and $21.90 \%$ respectively. As expected nowadays majority of students using the mobile phone during sleep time for chatting in social media, playing games, etc.

Table 4 showed association between degree of academic achievement and daily activities. Significant statistical differences were reported among academic degrees in laziness and fatigue after wake up time, laziness and fatigue during school time, lack of concentration during school time, difficulty in complete tasks during school time and inability to maintain wakefulness during school time $(p=0.002, p=0.002$, $\mathrm{p}=0.001, \mathrm{p}=0.001$ respectively). In addition, students with poor academic degrees reported more significant inability to maintain wakefulness and more liability to take nap during sleep time than good academic degrees $(\mathrm{p}=0.015, \mathrm{p}=0.029$ respectively). 


\section{Table 4 : Mean of the score of daily activities by general degree of academic achievement}

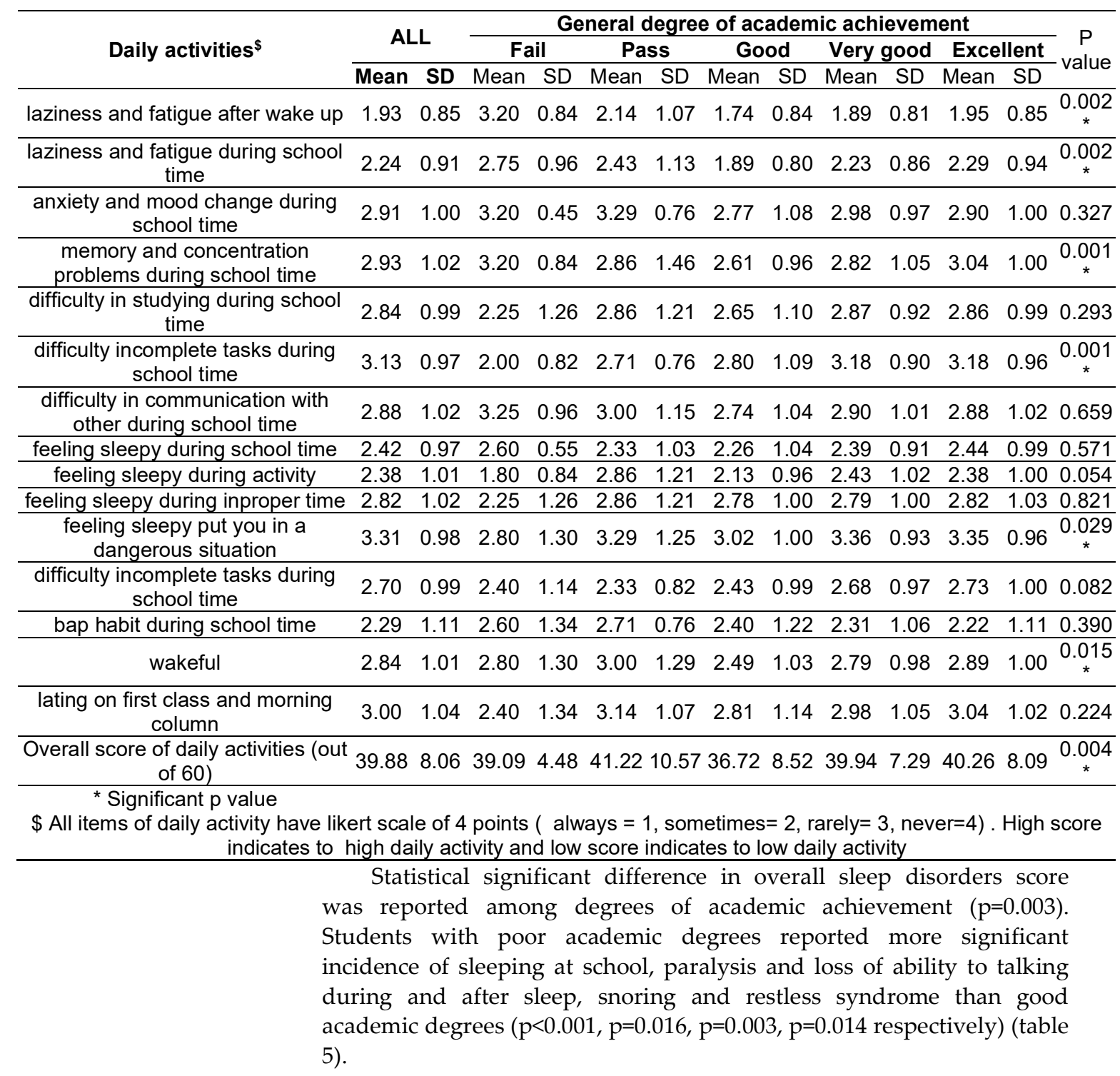




\begin{tabular}{|c|c|c|c|c|c|c|c|c|c|c|c|c|c|}
\hline \multirow{3}{*}{ Sleep disorder\$ } & \multirow{2}{*}{\multicolumn{2}{|c|}{ ALL }} & \multicolumn{10}{|c|}{ General degree of academic achievement } & \multirow{3}{*}{$\begin{array}{c}P \\
\text { value }\end{array}$} \\
\hline & & & \multicolumn{2}{|c|}{ Fail } & \multicolumn{2}{|c|}{ Pass } & \multicolumn{2}{|c|}{ Good } & \multicolumn{2}{|c|}{ Very good } & \multicolumn{2}{|c|}{ Excellent } & \\
\hline & $\begin{array}{c}\text { Mea } \\
\text { n }\end{array}$ & SD & $\begin{array}{c}\text { Mea } \\
\text { n }\end{array}$ & SD & Mean & SD & Mean & SD & Mean & SD & Mean & SD & \\
\hline difficulty in wake up at morning & 2.36 & 1.06 & 2.00 & 0.71 & 2.57 & 0.79 & 2.04 & 1.05 & 2.40 & 1.01 & 2.38 & 1.08 & 0.055 \\
\hline sleeping at school & 3.30 & 0.94 & 3.00 & 1.00 & 4.00 & 0.00 & 2.90 & 1.02 & 3.20 & 0.95 & 3.39 & 0.92 & $\begin{array}{c}<0.00 \\
1^{*}\end{array}$ \\
\hline sleep apnea & 3.32 & 0.94 & 3.00 & 1.00 & 2.71 & 1.11 & 3.24 & 1.04 & 3.35 & 0.89 & 3.33 & 0.94 & 0.335 \\
\hline headache after wake up & 2.94 & 1.05 & 2.40 & 1.34 & 3.57 & 1.13 & 2.73 & 1.06 & 2.95 & 1.06 & 2.95 & 1.02 & 0.113 \\
\hline strong desire to sleep after wake up & 2.10 & 1.06 & 2.20 & 1.10 & 2.86 & 1.21 & 1.98 & 0.98 & 2.19 & 1.06 & 2.03 & 1.05 & 0.066 \\
\hline repeated wake up suddenly without reason & 2.74 & 1.00 & 3.00 & 0.71 & 2.83 & 0.75 & 2.58 & 1.03 & 2.72 & 0.99 & 2.77 & 1.01 & 0.532 \\
\hline $\begin{array}{c}\text { paralysis and loss of ability to talking during \& } \\
\text { after sleep }\end{array}$ & 3.19 & 0.98 & 2.80 & 1.30 & 3.71 & 0.49 & .90 & 1.03 & 3.25 & 0.97 & 3.22 & 0.95 & $0.016^{*}$ \\
\hline effect of sleep on performance and study & 2.79 & 0.99 & 2.00 & 1.41 & 3.14 & 1.07 & 2.49 & 0.98 & 2.80 & 0.93 & 2.82 & 1.01 & $0.017^{*}$ \\
\hline snoring & 3.20 & 1.01 & 2.40 & 1.14 & 3.43 & 0.53 & 2.92 & 1.12 & 3.14 & 1.06 & 3.30 & 0.95 & $0.003^{*}$ \\
\hline sleepwalking & 3.38 & 0.95 & 2.60 & 1.14 & 3.43 & 0.98 & 3.30 & 1.03 & 3.37 & 0.91 & 3.39 & 0.96 & 0.415 \\
\hline Emotional disturbance when waking up & 2.73 & 1.04 & 2.20 & 1.30 & 3.29 & 0.95 & 2.73 & 1.09 & 2.70 & 1.00 & 2.71 & 1.05 & 0.499 \\
\hline Hard to set specific regular sleep time & 2.49 & 1.11 & 2.00 & 1.41 & 2.57 & 0.98 & 2.42 & 0.99 & 2.40 & 1.07 & 2.51 & 1.14 & 0.593 \\
\hline nightmare & 2.61 & 1.00 & 1.80 & 0.45 & 2.14 & 1.35 & 2.57 & 0.99 & 2.65 & 1.01 & 2.60 & 0.99 & 0.244 \\
\hline restless leg syndrome & 2.95 & 1.07 & 2.20 & 0.84 & 2.43 & 0.79 & 2.71 & 1.14 & 2.91 & 1.05 & 3.03 & 1.06 & $0.014^{*}$ \\
\hline Overall score of Sleep disorders (out of 56 ) & 40.04 & 7.70 & 33.69 & 5.61 & 42.41 & 8.25 & 37.48 & 7.33 & 40.03 & 7.49 & 40.41 & 7.66 & $0.003^{*}$ \\
\hline
\end{tabular}

$\$$ All items of Sleep disorder have likert scale of 4 points (always $=1$, sometimes $=2$, rarely $=3$, never $=4$ ). High score indicates to low Sleep disorder and low score indicates to high Sleep disorder

Excessive daytime sleepiness as assessed by Epworth Sleepiness Scale was also more statistically significant in poor academic degrees than good ones $(p=0.001)$. Significant differences among degrees of academic degrees were reported mainly in items of sleeping during sitting and reading and sleeping during sitting and talking with other $(\mathrm{p}$ $<0.001$ ) (table 6).

\begin{tabular}{|c|c|c|c|c|c|c|c|c|c|c|c|c|c|}
\hline \multirow{3}{*}{ Epworth Sleepiness $\$$} & \multirow{2}{*}{\multicolumn{2}{|c|}{ ALL }} & \multicolumn{10}{|c|}{ General degree of academic achievement } & \multirow{3}{*}{$\begin{array}{c}\mathrm{P} \\
\text { value }\end{array}$} \\
\hline & & & \multicolumn{2}{|c|}{ Fail } & \multicolumn{2}{|c|}{ Pass } & \multicolumn{2}{|c|}{ Good } & \multicolumn{2}{|c|}{ Very good } & \multicolumn{2}{|c|}{ Excellent } & \\
\hline & Mean & SD & Mean & SD & Mean & SD & Mean & SD & Mean & SD & Mean & SD & \\
\hline sleeping during sitting and reading & 1.26 & 0.93 & 2.20 & 1.30 & 0.86 & 1.07 & 1.66 & 0.94 & 1.27 & 0.90 & 1.20 & 0.92 & $\underset{*}{<0.001}$ \\
\hline sleeping during tv watching & 1.30 & 0.94 & 1.80 & 1.64 & 1.14 & 1.21 & 1.44 & 0.93 & 1.38 & 0.92 & 1.26 & 0.94 & 0.163 \\
\hline $\begin{array}{l}\text { sleeping during sitting in public place } \\
\text { without any activity }\end{array}$ & 0.95 & 0.99 & 1.40 & 1.14 & 0.57 & 0.98 & 0.97 & 0.85 & 1.03 & 1.04 & 0.92 & 0.98 & 0.349 \\
\hline sleeping during riding a car for 1 hour & 1.34 & 1.11 & 1.80 & 1.30 & 1.14 & 0.69 & 1.40 & 1.06 & 1.31 & 1.11 & 1.37 & 1.12 & 0.761 \\
\hline Lay comfortably during nap time & 1.78 & 1.09 & 1.75 & 1.50 & 1.33 & 1.03 & 1.87 & 0.97 & 1.65 & 1.06 & 1.85 & 1.09 & 0.090 \\
\hline $\begin{array}{c}\text { sleeping during sitting and talking with } \\
\text { other }\end{array}$ & 0.59 & 0.94 & 1.60 & 1.52 & 0.33 & 0.52 & 0.99 & 1.17 & 0.68 & 0.94 & 0.48 & 0.87 & $\underset{*}{<0.001}$ \\
\hline $\begin{array}{l}\text { Overall score of Epworth Sleepiness(out } \\
\text { of 18) }\end{array}$ & 7.23 & 3.44 & 10.76 & 7.42 & 5.14 & 4.38 & 8.38 & 3.76 & 7.32 & 3.13 & 7.06 & 3.38 & $0.001^{*}$ \\
\hline
\end{tabular}

$\$$ All items of Sleep disorder have likert scale of 4 points (Never feel sleepy $=0$, Rarely feel sleepy= 1 , Sometimes feel sleepy= 2 , Always feel sleepy=3). High score indicates to you may need to get more sleep, improve your sleep practices, or seek medical attention to determine why you are sleepy

Overall scores of sleep quality (daily activities score, sleep disorder score and epworth sleepiness score) showed significant correlation with general degrees of academic achievement in school students $(\mathrm{p}=0.005, \mathrm{p}=0.003, \mathrm{p}=0.002$ respectively) (table 7$)$. 
Table7 : Correlation between sleep quality and general degree of academic achievement in school students

\begin{tabular}{|c|c|c|}
\hline \multicolumn{3}{|c|}{ Table7 : Correlation between sleep quality and general degree of academic achievement in school students } \\
\hline & $\mathbf{r}$ & $\mathrm{P}$ value \\
\hline Overall score of daily activities & $.093^{* *}$ & .005 \\
\hline Overall score of Sleep disorders & $.099^{* *}$ & .003 \\
\hline Overall score of Epworth Sleepiness & $-.102^{* *}$ & .002 \\
\hline \multicolumn{3}{|c|}{$\begin{array}{l}\text { **. Correlation is significant at the } 0.01 \text { level (2-tailed). } \\
\qquad r=\text { Pearson correlation coefficient } \\
\text { ace is a directly relationship between daily activities and the general degree of academic achievement } \\
\text { e is a directly relationship between Sleep disorders and the general degree of academic achievement } \\
\text { is inversely relationship between Epworth Sleepiness and the general degree of academic achievement }\end{array}$} \\
\hline
\end{tabular}

\section{Discussion}

The sleep of children and adolescents normally shows changes in an expected way as the overall length of sleep decreases with age [12]. Advanced technology and modern lifestyles are risk factors for the occurrence of such changes, particularly for adolescents in urban centers [13,14]. Noise is one factor that can significantly disturb sleep with the volume of sound being an important consideration in this context. The current study showed that most participants were annoyed with noise and light. This agreed with a previously published study in which excessive light and noise were the main risk factors for sleep deprivation and disruption [15]. In a similar study conducted among student pharmacists, the results showed that more than half of them obtained less than seven hours of sleep at night during a typical school week with a large majority of these on the night prior to an examination. Almost half felt daytime sleepiness nearly every day. Longer sleep duration the night prior to exams was associated with higher grades and overall semester grade point averages [16]. Such results are in line with the current study as the largest proportion of the participating students sleep 4-6 hours. However, obtaining more than 7 hours of sleep per day is essential for optimum health and well-being ${ }^{[16]}$.

Children and teens/adolescents need more sleep than middle-aged adults. Normally, as a person ages the need for sleep is reduced, although this isn't the scenario when transitioning from childhood into adolescence. Adolescents need the same length of sleep as preteens. The adolescent needs nearly nine hours of sleep per night. However, the actuality of the situation rarely matches up to the ideal with adolescents often staying up late into the night. Then, when they awake early in the morning the sleep deficit contributes to overall sleep deprivation and daytime sleepiness. If sleep deprived, teens and adolescents are more likely to struggle in school. Students sometimes stay awake into the night doing homework or other assignments and then awaken early in the morning to go to school. Based on this, the average amount of sleep they receive during the week can be as little as 4-5 hours per night. They feel tired during their lessons and nothing seems to stay in their mind. They may want to go home and take a nap that will later lead to late-night studying. This is a common cycle among the students. Currently, school curricula are more demanding than ever before and contribute to sleep deprivation. This not only affects performance at school but also outside of school, at home and with friends. Additionally, school-related sleep deprivation contributes to several mental and physical health problems ${ }^{[17]}$.

In the Drake et al. ${ }^{[18]}$ study, poor grades at school were linked to sleepiness and sleep deprivation. When a child does not sleep 8-9 hours 
per night alertness and school performance become significantly impaired. The authors showed that students who did not succeed at school, had low school enjoyment and several absences slept less and had high levels of daytime sleepiness compared to those who succeeded at school [18].

Worldwide, caffeine is considered the most used psychoactive substance, with coffee, soda, and energy drinks being the most popular caffeine beverages. It improves behavioral and cognitive performance, even when sleep deprived. On the other hand, it can also cause sleeprelated problems [19]. More than half of the students participating in the current study were using energy drinks to stay awake at night.

Sharing a bed can be detrimental to sleep, particularly if one person suffers from a sleep problem. Snoring, restless leg syndrome, and sleep talking can disturb the other's sleep and decrease both sleep quality and duration. Additionally, the sleepless person may also wake up the other sleeper, which leads to both suffering from disturbed sleep. This is supported by the findings of Liu et al. [20], who reported that co-sleeping with a child puts the parents at risk for sleep deprivation and increased stress. Only a low percentage of students participating in the current study reported sharing a bed with others.

Napping during the day is beneficial as it reduces sleepiness and helps improve cognitive performance. An ideal nap lasts 10-30 minutes during the period from 1-5 p.m. If the nap lasts longer than recommended, recovery may take longer and the person might feel drowsy [21]. The largest proportion of students in the current study took naps during school.

The consequences of sleep problems, either due to insufficient sleep or an untreated sleep disorder, can be serious. Sleep problems have been associated with deficits in attention and academic performance, risk-taking behavior, depression, drowsy driving, and poor health [22-25]. The National Sleep Foundation found that high school students who experienced insufficient sleep or daytime sleepiness reported depressed mood and lower grades, whereas $80 \%$ of those who described getting enough sleep also achieved higher grades in school ${ }^{[26]}$. Some students in the current study reported sleep disorders that need to be examined and resolved to avoid any negative consequences.

Conflicts of Interest: The authors declare that they have no conflict of interest. 


\section{References:}

[1] j S, Brooks LJ, D'Ambrosio C, Hall WA, Kotagal S, Lloyd RM, Malow BA, Maski K, Nichols C, Quan SF, Rosen CL, Troester MM, Wise MS. Recommended amount of sleep for pediatric populations: a consensus statement of the American Academy of Sleep Medicine. J Clin Sleep Med. 2016; 12(6): 785-786.

[2] Watson NF, Badr MS, Belenky G, Bliwise DL, Buxton OM, Buysse D, et al. Recommended amount of sleep for a healthy adult: a joint consensus statement of the American Academy of Sleep Medicine and Sleep Research Society. Sleep. 2015; 38(6): 843-844.

[3] Matricciani L, Olds T, Petkov J. In search of lost sleep: secular trends in the sleep time of school-aged children and adolescents. Sleep Med Rev. 2012; 16(3); 203-211.

[4] Alsuhaymi ZS, Alreheli AQ, Alawfi AM, Alhazmi AM, Aljuhani RZ, Alruhaili EM, Alsuhimi SS. Impact of sleep habits on academic achievement among fourth-year medical students at Taibah University. Indo Am J Pharma Sci. 2019; 6(1): 790-800.

[5] Norell-Clarke A, Hagquist, C. Changes in sleep habits between 1985 and 2013 among children and adolescents in Sweden. Scand J Public Health. 2017; 45(8): 869-877. doi: $10.1177 / 1403494817732269$

[6] Hagenauer MH, Perryman JI, Lee TM, Carskadon MA. Adolescent changes in the homeostatic and circadian regulation of sleep. Dev. Neurosci. 2009; 31(4): 276-284.

[7] Owens J, Adolescent Sleep Working Group, Committee on Adolescence. Insufficient sleep in adolescents and young adults: An update on causes and consequences. Pediatrics. 2014; 134(3): :e921-e932.

[8] Astill RG, Van der Heijden KB, Van Ijzendoorn MH, Van Someren EJ. Sleep, cognition, and behavioral problems in school-age children: a century of research meta-analyzed. Psychol Bull 2012; 138(6): 1109-1138.

[9] Segura-Jiménez V, Carbonell-Baeza A, Keating XD, Ruiz JR, Castro-Piñero J. Association of sleep patterns with psycholo gical positive health and health complaints in children and adolescents. Qual Life Res. 2015; 24(4): 885-895.

[10] Seo JH, Kim JH, Yang KI, Hong SB. Late use of electronic media and its association with sleep, depression, and suicidality among Korean adolescents. Sleep Med, 2017; 29: $76-80$.

[11][No authors listed]. Detailed results of Jazan (gnerela population and housing census 2010-20100. General Authority for Statistics, Kingdom of Saudi Arabia. $<$ https://www.stats.gov.sa/en/1393>.

[12]Hinds PS, Hockenberry MJ, Gattuso JS, Srivastava DK, Tong X, Jones, H, et al. Dexamethasone alters sleep and fatigue in pediatric patients with acute lymphoblastic leukemia. Cancer. 2007; 110(10): 2321-2330.

[13] Mindell JA, Meltzer LJ, Carskadon MA, Chervin RD. Developmental aspects of sleep hygiene: findings from the 2004 National Sleep Foundation Sleep in America Poll. Sleep Med. 2009; 10(7): 771-779.

[14]Peixoto CA, da Silva AG, Carskadon MA Louzada FM. Adolescents living in homes without electric lighting have earlier sleep times. Behav Sleep Med 2009; 7(2): 7380 .

[15]Medic G, Wille M, Hemels ME. Short- and long-term health consequences of sleep disruption. Nat Sci Sleep. 2017; 9: 151-161.

[16] Cappuccio FP, D’Elia L, Strazzullo P, Miller MA. Sleep duration and all-cause mortality: A systematic review and meta-analysis of prospective studies. Sleep. 2010; 33(5): 585-592.

[17]Richter, R 2015. Among teens, sleep deprivation an epidemic. Stanford Medicine News Center. Accessed March 15, 2018. <https://med.stanford.edu/news/allnews/2015/10/among-teens-sleep-deprivation-an-epidemic.html $>$. 
[18] Drake C, Nickel C, Burduvali E, Roth T, Jefferson C, Badia P. The Pediatric Daytime Sleepiness Scale (PDSS): sleep habits and school outcomes in middle school children. Sleep. 2003; 26(4): 455-458.

[19] Chaudhary NS, Grandner MA, Jackson NJ, Chakravorty S. Caffeine consumption, insomnia, and sleep duration: results from a nationally representative sample. Nutrition. 2016; 32(11-12): 1193-1199.

[20]Liu X, Liu L, Wang R. Bed sharing, sleep habits, and sleep problems among Chinese school-aged children. Sleep. 2003; 26(7): 839-844.

[21]Partinen M, Huovinen M. [Unikoulu aikuisille. Opi selättämään unettomuus. Werner Söderström Osakeyhtiö. Helsinki: Bookwell Oy]. 2011.

[22] Pagel JF, Forister N, Kwiatkowki C. Adolescent sleep disturbance and school performance: the confounding variable of socioeconomics. J Clin Sleep Med. 2007; 3(1): 19-23.

[23] O’Brien EM, Mindell JA. Sleep and risk-taking behavior in adolescents. Behav Sleep Med. 2005; 3(3): 113-133.

[24] Cummings P, Koepsell TD, Moffat JM, Rivara FP. Drowsiness, counter-measures to drowsiness, and the risk of a motor vehicle crash. Inj Prev. 2001; 7(3): 194-199.

[25] Smaldone A, Honig JC, Byrne MW. Sleepless in America: inadequate sleep and relationships to health and well-being of our nation's children. Pediatrics 2007. 119 Suppl 1: S29-S37.

[26] Gaultney JF. The prevalence of sleep disorders in college students: impact on academic performance. J Am Coll Health. 2010; 59(2): 91-97. 